\title{
On the Investment Strategy, Effect of Inflation and Impact of Hedging on Pension Wealth during Accumulation and Distribution Phases.
}

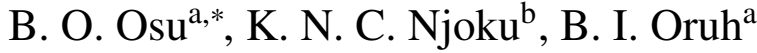 \\ ${ }^{a}$ Department of Mathematics, Michael Okpara University of Agriculture, Umudike, Nigeria. \\ ${ }^{b}$ Department of Mathematics, Imo State University, Owerri, Nigeria.
}

\begin{abstract}
This paper studies the various results obtained in literature on the investment strategy, the effect of inflation and impact of hedging on the Pension Wealth generation. The explicit solution of the constant relative risk aversion (CRRA) and constant absolute risk aversion (CARA) utility functions are obtained, both in the accumulation and distribution phase, using Legendre transform, dual theory, and change of variable techniques. It is established herein that the elastic parameter $(\beta)$ is not equal to one $(\beta \neq 1)$, based on the assumption of our model. Theorems are constructed and proved on the various wealth investment strategies. Observations and significant results are made and obtained, respectively in the comparison of our various utility functions and some previous results in literature. Sensitivity analysis and Simulations on the various utility functions and optimal strategies during the accumulation and distribution phase are presented; when the existence of a elastic parameter that is not equal to one, when there is existence of modifying factors, when there is need for diversification of investment, when there is no significant effect of the choice of risk aversion strategy on investment returns during inflation period, when there is hedging ability of Inflation-indexed Bond and Inflation-linked Stock and when there is insignificant effect of the orthogonal relationship between stock and time and nonpayment of pension benefits on the satisfaction of the investors.
\end{abstract}

Keywords: Hedging, constant relative risk aversion (CRRA), constant absolute risk aversion (CARA), Defined Contribution (DC), Constant elasticity of variance (CEV), optimal strategy.

Article History :

Received: 16 March 2020

Received in revised form: 29 April 2020

Accepted for publication: 29 April 2020

Published: 01 August 2020

(C)2020 Journal of the Nigerian Society of Physical Sciences. All rights reserved. Communicated by: T. Latunde

\section{Introduction}

One of the major challenges that old people are faced with is economic insecurity. By economic security we mean; having access to information, good health condition, good education, and many more, and security as it concerns work. Particularly, with the work related economic security, it is only but natural that at retirement age, they would become economically vul-

${ }^{*}$ Corresponding author tel. no: +2348032628251

Email address: osu.bright@mouau.edu.ng (B. O. Osu ) nerable. This is true because at old age, they are mentally, economically and physically inactive. Thus, in a bid to providing this required economic security, the National Pension Scheme was established [1].

Pension scheme, an economic security scheme that takes care of people at retirement was introduced in 1951, by colonial British administration, through an instrument called "Pension Ordinance" (The Nation, May, 2015). This Ordinance had retroactive effect from 1946, and was only applicable to those British officials that was posted to Nigeria (the Nation, May, 2015) and as such, attracted some legislation, such as; Pension 
law for Military, and many more. Roughly speaking, Pension can be said to be a specific pull fund into which a sum of money is paid during an employee's active years, and that is used in turn to service his/her periodic payments after retirement. According to the Encyclopedia Britannica, Pension is simply "a series of periodic" money payments made to a person(s) who retires from employment due to age barrier, challenges due to disability, or the completion of an agreed period of service. These payments continue as long as the beneficiary is alive, and even sometimes, extends to a next-of-kin. Pension consists of lump sum payment made to an employee upon his/her disengagement from active service. Payments are mostly made installmentally, every month. Pension scheme could be contributory (i.e., defined contribution plan), where a fixed amount of money is invested through the pension wealth, or noncontributory (i.e., defined benefit plan), where a fixed amount of money is paid to a person, regularly.

\section{Literature Review}

Recent publications in economic Journals and other reputable Mathematics and Science Journals have brought to light, variety of methods of optimizing investment strategies and returns. For instance, some researchers have made various contributions in this direction, particularly, in DC Pension Plan. In [2] a work on stochastic life styling optimal dynamic asset allocation for defined contribution pension plans was done. In their work, various properties and characteristics of the optimal asset allocation strategy, both with and without the presence of non-hedge-able salary risk were discussed. The significance of alternative optimal strategy by pension providers was established. In [3], a defined contribution (DC) pension plan investment problem during the accumulation phase under the multi-period mean-variance criterion was investigated. In [4] the optimal investment strategies for a DC pension fund under the Hull-White interest rate model. Under this model, the pension fund manager can invest capital in the bank account, stock index, and real estates was analysed. More so, [5] studied optimal pension management in a stochastic framework, they came out with a significant result.

In order to deal with optimal investment strategy, the need for maximization of the expected utility of the terminal wealth became necessary. Example, the Constant Relative Risk Aversion (CRRA) utility function, and (or) the Constant Absolute Risk Aversion (CARA) utility function were used to maximize the terminal wealth. In $[5,6]$ and $[7,8]$, CRRA was used to maximize terminal wealth. However, [9] used the CRRA and the CARA to maximize terminal wealth, and this triggered our research.

In [4] an optimal investment strategy for a DC pension fund with a stochastic salary, under the affine interest rate model was constructed. In this work, they introduced the notion of " Relative Pension Wealth", that is, where a pension plan member only considers his/her post-retirement benefit, the ratio of the pension wealth to his terminal salary. [9] considered a minimum guarantee while obtaining their optimal policy, under inflationary market. This minimum guarantee served as an amor- tization fund to make up for lost fund due to inflation. In 2009, [10] obtained an optimal investment strategy for annuity contracts, under the constant elasticity of variance (CEV) model. In his work made an assertion without a proof that the elastic parameter is not equal to 1 . The work did not consider in its pension wealth model the fact that the next-of-kin of the dead contributors should be paid some benefits. Neither did it consider categories of contributors, since in every employment period, a certain group of people of the same cadre is employed, therefore, in real life situation, the right thing should be multiple and categorized contributors. It did not also indicate that contributors will not willingly withdraw from the scheme. Sequel to the above, $[11,12]$ came up with a modification. However, these modifications are not void of mistakes, omission and limitations, maybe due to environmental and financial factors.

Hence, we further modify of this works, by considering different categories of contributors, with some other additional assumptions made. Our task in this work is to compare the various results obtained in literature, and categorically state the optimal Policy in the various trading period.

\section{Preliminaries}

We start with a complete and frictionless financial market that is continuously open over the fixed time interval [ $0, T]$, for $T>0$, representing the retirement time of any plan member.

We assume that the market is composed of the risk-free asset (cash), and risky asset (stock). Let $(\Omega, F, P)$ be a complete probability space, where $\Omega$ is a real space and $P$ is a probability measure, $\left\{w_{s}(s), w_{t}(t)\right\}$ are two standard non-orthogonal Brownian motions, $\left\{F_{s}(s), F_{t}(t)\right\}$ are right continuous filtrations whose information are generated by the two standard Brownian motions $\left\{w_{s}(s), w_{t}(t)\right\}$, whose sources of uncertainties are respectively to the stock market and time evolution.

\subsection{Materials and Methods}

Assume we represent $u=u_{s}$ as the strategy and we define the utility attained by the contributor from a given state $y$ at time $t$ as

$$
\varnothing_{u}(t, r, y)=E_{u}[U(Y(t)): r(t), \mathrm{y}(t)=y]
$$

where $t$ is the time, $r$ is the short interest rate and $y$ is the wealth. Our interest here is to find the optimal value function

$$
\varnothing(t, r, y)=\operatorname{Sup} \varnothing_{u}(t, r, y)
$$

and the optimal strategy $u^{*}=u_{s}^{*}$ such that

$$
\varnothing_{u^{*}}(t, r, y)=\varnothing(t, r, y)
$$

\subsection{Legendre Transformation}

The Legendre transform and dual theory help to transform the nonlinear partial differential equation that is formed due to 1 , to a linear partial differential equation. 
Theorem 1 [13] : Let $f: R^{n} \rightarrow R$ be a convex function for $z>0$, then the Legendre transform is defined as;

$$
L(z)=\max _{y}\{f(y)=z y\},
$$

where $L(z)$ is the Legendre dual of $f(y)$.

Since $f(y)$ is convex, from theorem 1 we define the Legendre transform

$$
\begin{aligned}
\hat{\varnothing}(t, r, z)=\quad & \sup \{\varnothing(t, r, y)-z y\} \\
& 0<y<\infty, 0<t<T,
\end{aligned}
$$

where $\hat{\varnothing}$ is the dual of $\varnothing$ and $z>0$ is the dual variable of $x$. The value of $y$ where this optimum is attained is denoted by $h(t, r, z)$, so that

$$
h(t, r, z)=\inf \{y: \varnothing(t, r, y) \geq z y+\hat{\varnothing}(t, r, z)\}
$$

The function $h$ and $\hat{\phi}$ are closely related and can be referred to as the dual of $\phi$. These functions are related as follows

$$
\hat{\varnothing}(t, r, z)=\varnothing(t, r, y)-z h
$$

where,

$$
h(t, r, z)=y, \varnothing_{y}=z, h=-\hat{\varnothing}_{z} .
$$

At terminal time $T$, we denote

$\hat{U}=\operatorname{Sup}\{U(y)-z y: 0<y<T\}$

and

$\varnothing(z)=\operatorname{Sup}\{U(y) \geq z y+\bar{U}(z)\}$.

As a result

$$
\varnothing(z)=U^{-1}(z),
$$

where $\phi$ is the inverse of the marginal utility $U$ and note that $\varnothing(T, r, y)=U(y)$.

At terminal time $T$, we can define

and

$$
h(T, r, y)=\inf _{y>0}\{y: U(y) \geq z y+\hat{\phi}(t, r, z)\}
$$

$\hat{\phi}(t, r, y)=\operatorname{Sup}_{y>0}\{U(y)-z y\}$

so that $h(T, r, z)=U^{-1}(z)$.

\section{The Model}

This section introduces the financial market and proposes the optimization problems in the Pension distribution phase. (i.e., Pension payment/disbursement period).

\subsection{The Financial Market}

Here, we consider a financial market that consists of a riskfree asset (i.e., cash in the bank) and a risky asset (stock).

Let the risk-free asset $C_{t}$, say, at any positive time, $t$, evolve thus;

$$
d C_{t}=r C_{t} d t
$$

where $r$ represents constant rate of interest. Next, we denote the price of the risky asset (stock) at any positive time $r$, by $S_{t}$, as in $[11,14,15]$ thus;

$$
d S_{t}=\mu S_{t} d t+k S_{t}^{\beta+1} d W_{t}
$$

where $\mu(\mu>r)$ represents the instantaneous rate of return on stock, $\beta(\beta \leq 0)$ is the elastic constant parameter, $k$ is a constant, $k S_{t}^{\beta}$ represents the instantaneous volatility.

Let $\left\{W_{t} ; t \geq 0\right\}$ denote a standard Brownian motion, defined on a probability space, $(\Omega, F, P)$ where $F=\left\{F_{t}\right\}$ is an augmented filtration generated by the Brownian motion.

\section{Model Assumption}

Consistent with the Nigerian Pension Reform Act of 2004 [1], we make the following assumptions:

1. The Pension Scheme accumulates wealth.

2. There are different categories of contributions.

3. The contributors will not willingly withdraw from the scheme.

4. Payments are made to the retirees.

5. An accumulated amount is paid to the Next-of-kin of the dead contributors, at the instance of death by any contributor(s).

6. A certain amount is retained from the payment made to the families of dead contributors, by the Pension managers (i.e., management fee).

\subsection{Model Formation (i.e., the Optimization Program)}

The fund accruing from the contributors can be invested in both Bank and stock. Particularly, the fund to be invested by the fund manager is the surplus, which is the fund that is available after each period of routine disbursements. That is, let the contribution process be:

$$
d y=\left(1+\theta_{i}\right) C_{i+1} d t
$$

and the payment process

$$
d j=b_{i+1} d t+\left(a_{i+1}-\eta\right) d W_{s}
$$

Then the surplus

$$
\begin{array}{rc}
d P= & d y-d j=\left(1+\theta_{i}\right) C_{i+1} d t- \\
& {\left[b_{i+1} d t+\left(a_{i+1}-\eta\right) d W_{s}\right]} \\
= & \left(C_{i+1}+\theta_{i} C_{i+1}-b_{i+1}\right) d t- \\
\left(a_{i+1}-\eta\right) d W_{s}
\end{array}
$$

Therefore, our task here is to construct an optimal investment strategy for the assets for the remaining periods after retirement, to enable us maximize the expected utility at each retirement period.

Without loss of generality, the pension wealth is denoted by at any time $0<t<T<T+N$ and it evolves stochastically, thus (See [12]):

$$
\begin{aligned}
& d Y(t)=\quad u_{s} Y(t) \frac{d S_{t}}{d S_{t}}+ \\
& \left(1-u_{s}\right) Y(t) \frac{d C_{t}}{d C_{t}}+ \\
& \left(C_{i+1}+\theta_{i} C_{i+1}\right) d t-\left(a_{i+1}-\eta\right) d W_{s}
\end{aligned}
$$

$i=0,1, \ldots, n-1$ and $\theta_{i}=0, \theta_{1}=1, \theta_{2}=2, \ldots, \theta_{i}$ (an integer) $=$ staff loading, where; $a_{i+1}>0$ represents various amount that 
is paid to the Next-of-Kin of the dead contributors, $b_{i+1}>0$ represents various amount paid to retired contributors, $c_{i+1}>0$ represents various amount contributed, $\eta$ is the service charge deducted from the $a_{i+1}$.

However, relevant to the provisions of the Nigerian Pension Reform Act of 2004, on the eligibility condition for signing up on the Pension Scheme, by both government and private sectors, we have;

$$
\begin{aligned}
& d Y(t)=\quad u_{s} Y(t) \frac{d S_{t}}{d S_{t}}+ \\
& \left(1-u_{s}\right) Y(t) \frac{d C_{t}}{d C_{t}}+ \\
& \left(C_{i+1}+\theta_{i} C_{i+1}-b_{i+1}\right) d t-\left(a_{i+1}-\eta\right) d W_{s}
\end{aligned}
$$

$i=4,5, \ldots, n-1$, and $\theta_{4}=4, \theta_{5}=5, \theta_{6}=6, \ldots, \theta_{n}=n(\mathrm{a}$ positive integer $)=$ staff loading.

Assuming, $b_{i+1}=C_{i+1}+r_{d} C_{i+1} ; r<r_{d}$, and $r_{d}$ represents discounted interest, then

$$
\begin{aligned}
d Y(t)= & u_{s} Y(t) \frac{d S_{t}}{d S_{t}}+\left(1-u_{s}\right) Y(t) \frac{d C_{t}}{d C_{t}}+ \\
& \left(\theta_{i}-r_{d}\right) C_{i+1} d t-\left(a_{i+1}-\eta\right) d W_{s},
\end{aligned}
$$

$i=4,5, \ldots, n-1$, and $\theta_{4}=4, \theta_{5}=5, \theta_{6}=6, \ldots, \theta_{n}=n, \theta_{i}>0$ (integer) $=$ staff loading.

Taking into 12, 13 and 18, one obtains the wealth process

$$
\begin{aligned}
& d Y(t) u_{s} Y(t)\left[\mu d t+k S^{\beta} d W_{t}\right] \\
& +\left(1-u_{s}\right) Y(t) r d t+\left(\theta_{i}-r_{d}\right) C_{i+1} d t-\left(a_{i+1}-\eta\right) d W_{s} \\
& u_{s} Y(t) \mu d t+u_{s} Y(t) k S^{\beta} d W_{t}+Y(t) r d t+u_{s} Y(t) r d t \\
& +\left(\theta_{i}-r_{d}\right) C_{i+1} d t-\left(a_{i+1}-\eta\right) d W_{s} \\
& \left(u_{s} Y(t) \mu+Y(t) r-u_{s} Y(t) r+\left(\theta_{i}-r_{d}\right) C_{i+1}\right) d t \\
& +u_{s} Y(t) k S^{\beta} d W_{t}-\left(a_{i+1}-\eta\right) d W_{s}
\end{aligned}
$$

$i=4,5, \ldots, n-1$, and $\theta_{4}=4, \theta_{5}=5, \theta_{6}=6, \ldots, \theta_{n}=n, \theta_{i}>0$ (integer) $=$ staff loading.

Based on the wealth process in 19, the Pension manager seeks a strategy, $u_{t}^{*}$, which maximizes the utility function, such that $u_{t}^{*}=\max E(U(Y(T))), \forall u(t)$. Where $u(\bullet)$ is an increasing concave utility function, which satisfies the Inada conditions; $U^{\prime}(+\infty)=0$, and $U^{\prime}(0)+\infty,($ cf. [10]).

\subsection{Equations for Utility Functions and Optimal Policies}

For CRRA Utility Function in the Pension Distribution Phase under Noninflationary Market

$$
\begin{aligned}
& h(t, r, z)=z^{\frac{1}{p-1}} e^{\left\lceil\frac{r}{1-p}-r+\frac{1}{q(2-p)}-\frac{u_{s}^{2}}{k^{2}(1-p)}+\frac{u_{s}^{2}(2-p) j}{2 k^{2}(1-p)}\right\rceil[T-t]} \\
& -e^{r t}\left[2 k\left(\theta_{i}-r_{d}\right) C_{i+1}+\alpha \gamma u_{s}\left(a_{i+1}-\eta\right)\right][T-t]
\end{aligned}
$$

and

$$
\begin{aligned}
& u_{s}^{*}=\frac{\alpha \gamma\left(a_{i+1}-\eta\right)}{2 X(t) k}-u_{z}(p-1) z^{\frac{2 p-3}{p-1}} \\
& \times e^{\left\lceil\frac{r}{1-p}-r+\frac{1}{q(2-p)}-\frac{u_{s}^{2}}{k^{2}(1-p)}+\frac{u_{s}^{2}(2-p) j}{2 k^{2}(1-p)}\right\rceil[T-t]}
\end{aligned}
$$

where as in [16], $c_{1}=\frac{1}{2}\left(a_{i+1}-\eta\right)^{2}+\frac{3}{8}(\alpha \gamma)^{2}\left(a_{i+1}-\eta\right)^{2}$, as required. For CARA Utility Function in the Distribution Phase under Noninflationary Market

$$
g^{*}(t . s . z)=q^{-1} e^{r(T-t)} \ln z+q^{-1} e^{r(T-t)}\left(\int w(T) d T-\right.
$$

$$
\begin{aligned}
& \left.\int w(t) d t+e^{-\frac{(\alpha \gamma)^{2} k\left(a_{i-1}-\eta\right)}{2} q \int s(t) d t}\right) \\
& -q^{-1} e^{r(T-t)} \frac{u_{L}^{2}}{2 k^{2}}\left[\int e^{-\frac{(\alpha \gamma)^{2} k\left(a_{i-1}-\eta\right)}{2} q \int s(t) d t} d t\right. \\
& \left.-\int e^{-\frac{(\alpha \gamma)^{2} k\left(a_{i-1}-\eta\right)}{2} q \int s(T) d T} d T\right] \\
& +e^{-r t}\left[\int e^{r t} \frac{2 k\left(\theta_{i}-r_{d}\right) C_{i+1}+\alpha \gamma u_{L}\left(a_{i+1}-\eta\right)}{2 k} d t\right. \\
& \left.-e^{r T} \frac{2 k\left(\theta_{i}-r_{d}\right) C_{i+1}+\alpha \gamma u_{L}\left(a_{i+1}-\eta\right)}{2 k} d T\right]
\end{aligned}
$$

and

$$
\begin{aligned}
& u_{s}^{*}=\frac{\alpha \gamma\left(a_{i+1}-\eta\right)}{2 X(t) k S^{\beta}}+u_{L} e^{(T-t)} \frac{\alpha \gamma}{2 q X(t) S^{\beta-1}} \frac{d}{d S} \\
& \times\left(e^{-(\alpha \gamma)^{2} k\left(a_{n+1}-\eta\right) q \int S(t) d t} \int e^{-(\alpha \gamma)^{2} k\left(a_{n+1}-\eta\right) q \int S(T) d T} d T\right)
\end{aligned}
$$

where $q>0, \mu=u_{L}+r$ (See [17]). For CRRA Utility Function in the Accumulation Phase under Inflationary Market

$$
\begin{aligned}
& u_{S}^{*}=\frac{\sigma_{p}^{I}}{\sigma_{s}^{s}}-\left(\frac{-\lambda_{1} \sigma_{s}^{s}-\lambda_{2} \sigma_{s}^{I} \theta_{I}+\sigma_{s}^{I} \sigma_{p}^{I}+\sigma_{s}^{I}\left(\theta_{I}-\frac{\sigma_{p}^{I}}{2}\right)}{\sigma_{s}^{s}}\right) \\
& \times \frac{1}{p-1} \frac{e^{\left\{a \pm\left(a^{2}-2 k_{2} H\right)^{1 / 2} k_{2}^{-1} t\right\}}}{e^{\left\{a \pm\left(a^{2}-2 k_{2} H\right)^{1 / 2} k_{2}^{-1} T\right\}}}\left(\frac{e^{\left\{a \pm\left(a^{2}-2 k_{2} H\right)^{1 / 2} k_{2}^{-1} T\right\}}}{e^{\left\{a \pm\left(a^{2}-2 k_{2} H\right)^{1 / 2} k_{2}^{-1} t\right\}}}\right. \\
& \left.-\frac{\rho_{*} z^{\frac{1}{p-1}}}{k\left(1-e^{-\rho_{*}(T-t)}\right)}\right) .
\end{aligned}
$$

$u_{B}^{*}=\frac{\sigma_{p}^{I}}{\sigma_{I}}-\frac{\sigma_{p}^{I} \sigma_{s}^{I}}{\sigma_{s}^{s} \sigma_{I}}$

$+\left\{\frac{\left[\left(\sigma_{s}^{I}\right)^{2} \theta_{I}-\sigma_{s}^{I} \sigma_{I} \sigma_{p}^{I}-\sigma_{s}^{I} \lambda_{1} \sigma_{s}^{s}\right]}{\left(\sigma_{s}^{s}\right)^{2}}\right.$

$\left.-\frac{\left(\sigma_{s}^{I}\right)^{2} \lambda_{2} \theta_{I}+\frac{\left(\sigma_{s}^{I}\right)^{2} \sigma_{p}^{I}}{2}+\frac{\sigma_{s}^{s} \sigma_{s}^{I} \sigma_{p}^{I}}{2}}{\left(\sigma_{s}^{s}\right)^{2}}\right\} \frac{1}{p-1}$

$+\frac{e^{\left\{a \pm\left(a^{2}-2 k_{2} H\right)^{\frac{1}{2}} k_{2}^{-1} t\right\}}}{e^{\left\{a \pm\left(a^{2}-2 k_{2} H\right)^{\frac{1}{2}} k_{2}^{-1} T\right\}}}\left(\frac{e^{\left\{a \pm\left(a^{2}-2 k_{2} H\right)^{\frac{1}{2}} k_{2}^{-1} T\right\}}}{e^{\left\{a \pm\left(a^{2}-2 k_{2} H\right)^{\frac{1}{2}} k_{2}^{-1} t\right\}}}\right.$

$\left.-\frac{\rho_{*} z^{\frac{1}{p-1}}}{k\left(1-e^{-\rho_{*}(T-t)}\right)}\right)$

$+\frac{\theta_{I}}{p-1} \frac{\left.e^{\left\{a \pm\left(a^{2}-2 k_{2} H\right)^{\frac{1}{2}} k_{2}^{-1} t\right.}\right\}}{e^{\left\{a \pm\left(a^{2}-2 k_{2} H\right)^{\frac{1}{2}} k_{2}^{-1} T\right\}}}\left(\frac{e^{\left\{a \pm\left(a^{2}-2 k_{2} H\right)^{\frac{1}{2}} k_{2}^{-1} T\right\}}}{e^{\left\{a \pm\left(a^{2}-2 k_{2} H\right)^{\frac{1}{2}} k_{2}^{-1} t\right\}}}\right.$

$\left.-\frac{\rho_{*} z^{\frac{1}{p-1}}}{\sigma_{I} k\left(1-e^{-\rho_{*}(T-t)}\right)}\right)$,

$\rho_{*}=\frac{1}{2} \rho_{5}+\rho_{1}, \sigma_{p}^{I}=\sigma_{p}^{s}$ 
where $\rho_{1}, \rho_{2}, \ldots \rho_{5}$ are as in [16].

$$
\begin{aligned}
& H=\frac{\rho_{5}}{2(1-p)}+\frac{\rho_{1}}{1-p} \\
& -\frac{1}{2} \rho_{5}-\frac{1}{2} \rho_{1}+\frac{2\left(2 \theta_{I}^{2} \frac{1}{2}\left(\sigma_{p}^{I}\right)^{2}-\theta_{I} \sigma_{p}^{I}+\rho_{2}+\rho_{4}\right)}{1-p} \\
& -\frac{(2-p)\left(2 \theta_{I}^{2} \frac{1}{2}\left(\sigma_{p}^{I}\right)^{2}-\theta_{I} \sigma_{p}^{I}+\rho_{2}+\rho_{4}\right)}{(1-p)^{2}} \\
& N(t)=\frac{2 b[t-T]}{k_{1}}, \\
& d_{1}=\frac{4 b}{2 k_{1}}, \\
& d_{2}=0,
\end{aligned}
$$

\section{Sensitivity Analysis}

For CRRA Utility Function in the Pension Distribution Phase under Noninflationary Market; Setting $\alpha \gamma=0$ (that is, saying that stock and time have orthogonal relationship), and $a_{i+1}-\eta=$ 0 (that is, no money is paid to the Next-of-kin of the dead contributors) in equations ?? and 20 yield, respectively;

$$
\begin{aligned}
& h(t, s, z)=z^{\frac{1}{p-1}} \\
& e^{\left\lceil\frac{r}{1-p}-r+\frac{1}{q(2-p)}-\frac{u_{s}^{2}}{k^{2}(1-p)}+\frac{u_{s}^{2}(2-p) j}{2 k^{2}(1-p)}\right\rceil[T-t]} \\
& -e^{r t}\left[2 k\left(\theta_{i}-r_{d}\right) C_{i+1}\right][T-t], \\
& u_{s}^{*}=-u_{z}(p-1) z^{\frac{2 p-3}{p-1}} \\
& e^{-\left\lceil\frac{r}{1-p}-r+\frac{1}{q(2-p)}-\frac{u_{s}^{2}}{k^{2}(1-p)}+\frac{u_{S}^{2}(2-p) j}{2 k^{2}(1-p)}\right\rceil[T-t]}
\end{aligned}
$$

and

$$
\begin{aligned}
& h(t, s, z)=z^{\frac{1}{p-1}} \\
& e^{\left\lceil\frac{r}{1-p}-r+\frac{1}{q(2-p)}-\frac{u_{s}^{2}}{k^{2}(1-p)}+\frac{u_{s}^{2}(2-p) j}{2 k^{2}(1-p)}\right\rceil[T-t]} \\
& -e^{-r t}\left[2 k\left(\theta_{i}-r_{d}\right) C_{i+1}\right][T-t], \\
& u_{s}^{*}=-u_{s}(p-1) z^{\frac{2 p-3}{p-1}} \\
& e^{-\left\lceil\frac{r}{1-p}-r+\frac{1}{q(2-p)}-\frac{u_{s}^{2}}{k^{2}(1-p)}+\frac{u_{s}^{2}(2-p) j}{2 k^{2}(1-p)}\right\rceil[T-t]}
\end{aligned}
$$

For CARA Utility Function in the Pension Distribution Phase under Noninflationary Market, setting $\alpha \gamma=0$ (that is, saying that stock and time have orthogonal relationship), and $a_{i+1}-$ $\eta=0$ (that is, no money is paid to the Next-of-kin of the dead contributors) in equations 21 and 22 yield, respectively;

$$
\begin{gathered}
h(t . s . z)=q^{-1}\left[e ^ { r ( T - t ) } \left(\ln z+\int w(T) d T-\right.\right. \\
\left.\left.\int w(t) d t+\frac{u_{L}^{2}}{2 k^{2}}\left[\int(d t-d T)\right]\right)\right]+
\end{gathered}
$$

Table 1. Parameters and their respective values

\begin{tabular}{lcc}
\hline Name of Parameters & Symbol Used & Values \\
Constant rate of interest & $r$ & 0.02 \\
Expected stock returns & $\mu$ & 0.10 \\
Instantaneous stock returns & $u_{s}=u_{L}$ & 0.07 \\
Stock volatility & $k$ & 0.55 \\
Risk aversion & $q=p$ & 0.50 \\
Rate of contribution & $r_{d}$ & 0.075 \\
Management fee & $\eta^{i}$ & 0.025 \\
\hline
\end{tabular}

$$
\begin{aligned}
& e^{-r t}\left[\int e^{r t} \frac{2 k\left(\theta_{i}-r_{d}\right) C_{i+1}}{2 k} d t\right. \\
& \left.-e^{r T} \frac{2 k\left(\theta_{i}-r_{d}\right) C_{i+1}}{2 k} d T\right]
\end{aligned}
$$

$$
u_{L}^{*}=u_{L} e^{r(T-t)}
$$

and

$$
\begin{gathered}
h(t . s . z)=-q^{-1}\left[e ^ { r ( T - t ) } \left(\ln z+\int w(T) d T\right.\right. \\
\left.\left.-\int w(t) d t+\frac{u_{L}^{2}}{2 k^{2}}\left[\int(d t-d T)\right]\right)\right] \\
+e^{-r t}\left[\int e^{r t} \frac{2 k\left(\theta_{i}-r_{d}\right) C_{i+1}}{2 k} d t\right. \\
\left.-e^{r T} \frac{2 k\left(\theta_{i}-r_{d}\right) C_{i+1}}{2 k} d T\right] \\
u_{S}^{*}=u_{L} e^{-i \omega t}-\frac{\alpha \gamma}{2 Y(t) S^{\beta-2}} q^{-1} F^{\prime}(S)
\end{gathered}
$$

where $=F^{\prime}(S)=\frac{1}{q} \frac{d}{d S}\left(\int d T\right)$. For CARA Utility Function in the Pension Accumulation Phase under Inflationary Market; Setting $\sigma_{p}^{I}=\sigma_{s}^{I}=\theta_{I}=0$, makes the optimal strategies in equations 23 and 24 would be of the form of the [4]. What this means is that in the absence of inflation vis-a-vis risk premium due to inflation, we would have a model of the form of [18].

\section{Numerical Simulation}

A numerical example of the proposed model was given to demonstrate the dynamic behavior of a DC pension fund and optimal investment strategy. Nigeria-National Pension Fund Administration (NNPFA) real data was used to illustrate the efficiency of the model. The parameters used are summarized in the table below, for $T=30$. $t=0,5,15,20,25,30$, with $i=$ $4,5,6, \ldots, n-1$ and $\theta_{4}=4, \theta_{5}=5, \theta_{6}=6, \theta_{7}=7, \ldots, \theta_{n}=n$. Assume for perfect correlation $\alpha \gamma=1, a_{i+1}=274,464.68 \times$ $30=8233940.4$ as at $30^{\text {th }}$ June (for April, 2016), 2019, $X(t)=$ $0.07 \times 8233940.4+82333940.4=576375.83+8233940.4=$ $8810316.2, \beta=0, S(t)=7657564.6, X\left(t_{0}\right)=8233940.4$, which is initial Pension wealth for 30 contributors, from January 2015 to April 2016 of IMSU Academic Staff of 2014 set (TRUST FUND PFA Returns of June, 2019).

For CRRA Utility Function in the Pension Distribution Phase under Noninflationary Market, below are various three-dimensional 
Table 2. The numerical values for the optimal policy and the Dual variable for the time period from 0 to 29th year, for the CRRA model.

\begin{tabular}{cccccccccccccccc}
\hline $\mathrm{U}$ & 1.57 & 1.52 & 1.51 & 1.50 & 1.49 & 1.39 & 0.38 & 0.38 & 0.34 & 0.32 & 0.46 & 0.42 & 0.41 & 0.34 & 0.32 \\
$\mathrm{Z}$ & 1 & 2 & 3 & 4 & 5 & 6 & 7 & 8 & 9 & 10 & 11 & 12 & 13 & 14 & 15 \\
$\mathrm{~T}$ & 0 & 1 & 2 & 3 & 4 & 5 & 6 & 7 & 8 & 9 & 10 & 11 & 12 & 13 & 14 \\
\hline $\mathrm{U}$ & 1.46 & 0.42 & 0.41 & 0.34 & 0.32 & 1.41 & 0.40 & 1.39 & 0.39 & 0.38 & 0.38 & 0.34 & 0.32 & 0.46 & 0.42 \\
$\mathrm{Z}$ & 16 & 17 & 18 & 19 & 20 & 21 & 22 & 23 & 24 & 25 & 26 & 27 & 28 & 29 & 30 \\
$\mathrm{~T}$ & 15 & 16 & 17 & 18 & 19 & 20 & 21 & 22 & 23 & 24 & 25 & 26 & 27 & 28 & 29 \\
\hline
\end{tabular}

Table 3. Values for optimal policy, dual variable and continuous time for CRRA model, when there is orthogonal relationship between time and stock.

\begin{tabular}{ccccccccccccccccc}
\hline $\mathrm{U}$ & 0.47 & 0.042 & 0.041 & 0.040 & 0.039 & 0.038 & 0.038 & 0.34 & 0.32 & 0.46 & 0.42 & 0.41 & 0.34 & 0.32 & 0.46 \\
$\mathrm{Z}$ & 1 & 2 & 3 & 4 & 5 & 6 & 7 & 8 & 9 & 10 & 11 & 12 & 13 & 14 & 15 \\
$\mathrm{~T}$ & 0 & 1 & 2 & 3 & 4 & 5 & 6 & 7 & 8 & 9 & 10 & 11 & 12 & 13 & 14 \\
\hline $\mathrm{U}$ & 0.42 & 0.41 & 0.34 & 0.32 & 0.41 & 1.40 & 0.39 & 0.39 & 0.38 & 0.38 & 0.34 & 0.32 & 0.46 & 0.42 & 0.42 \\
$\mathrm{Z}$ & 16 & 17 & 18 & 19 & 20 & 21 & 22 & 23 & 24 & 25 & 26 & 27 & 28 & 29 & 30 \\
$\mathrm{t}$ & 15 & 16 & 17 & 18 & 19 & 20 & 21 & 22 & 23 & 24 & 25 & 26 & 27 & 28 & 29 \\
\hline
\end{tabular}

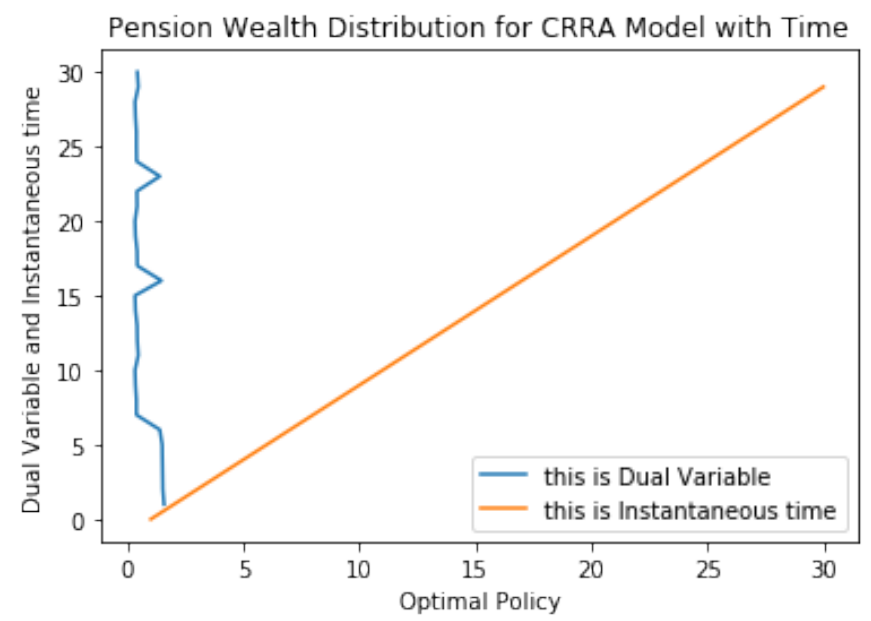

Figure 1. The graph of dual variable and instantaneous time against optimal policy for CRRA Mode.

tables (that is, Tables 1,2 and 3 and their plots respectively in Figures 1, 2 and 3).

Table 4 above are various three-dimensional used in the plot of Figure 3.

For CARA Utility Function in the Distribution Phase under Noninflationary Market, Table 6 below are various threedimensional used in the plot of Figure 6.

Table 7 above are various three-dimensional used in the plot of Figure 7.

Table 8 above are various three-dimensional used in the plot of Figure 8.

\section{Discussion}

For CRRA Utility Function in the Distribution Phase under Noninflationary Market; Result shows that if we set $\alpha \gamma=0$ and $a_{i+1}-\eta=0$, then in equations 24 and 27, the orthogonal relation between stock and time has the same effect on contributors' satisfaction.

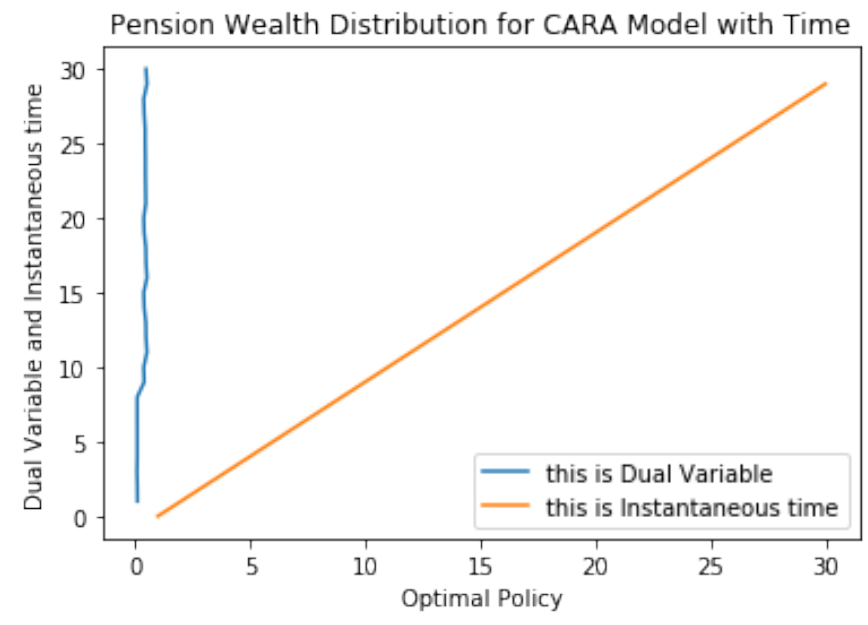

Figure 2. The graph of dual variable and instantaneous time against optimal policy for CRRA Model, when there is orthogonal relationship between time and stock.

In equations 26 and 28 , we have the same negative effect (i.e., a decline in stock investment). Considering the dual relationship between pension wealth, it follows that the optimal strategy will appreciate frictionless, which is unrealistic. There exists a modifying factor which depends on time, only, just like in [13] and this modifying factor controls investment decision of the PPM. From proposition 4.4.1 in [14], result shows that the elastic parameter, $\beta$ is not equal to 1 (the elastic parameter $\beta \neq 1$ ).

For CARA Utility Function in the Distribution Phase under Noninflationary Market, results show that if we set $\alpha \gamma=0$ and $a_{i+1}-\eta=0$ then in equation 30 and 32, the orthogonal relation between stock and time has the same effect on contributor's satisfaction. However, both have significant effect. In equations 31 and 33 , investments made in stock slightly reduce, vis-a-vis the stock returns. Though, more money is invested in cash account than stock when there is orthogonal relationship between stock and time. Here, there are minimal stock returns at each trading 
Table 4. Values for optimal policy, dual variable and continuous time for CRRA model, when no payment was made to the next of kin of the dead contributors.

\begin{tabular}{cccccccccccccccc}
\hline $\mathrm{U}$ & 0.047 & 0.042 & 0.041 & 0.040 & 0.039 & 0.039 & 0.038 & 0.38 & 0.34 & 0.32 & 0.46 & 0.42 & 0.41 & 0.34 & 0.32 \\
$\mathrm{Z}$ & 1 & 2 & 3 & 4 & 5 & 6 & 7 & 8 & 9 & 10 & 11 & 12 & 13 & 14 & 15 \\
\hline $\mathrm{t}$ & 0 & 1 & 2 & 3 & 4 & 5 & 6 & 7 & 8 & 9 & 10 & 11 & 12 & 13 & 14 \\
$\mathrm{U}$ & 0.46 & 0.42 & 0.41 & 0.34 & 0.32 & 1.41 & 0.40 & 0.39 & 0.39 & 0.38 & 0.38 & 0.34 & 0.46 & 0.32 & 0.46 \\
$\mathrm{Z}$ & 16 & 17 & 18 & 19 & 20 & 21 & 22 & 23 & 24 & 25 & 26 & 27 & 28 & 29 & 30 \\
$\mathrm{t}$ & 15 & 16 & 17 & 18 & 19 & 20 & 21 & 22 & 23 & 24 & 25 & 26 & 27 & 28 & 29 \\
\hline
\end{tabular}

Table 5. Values for optimal policy, dual variable and continuous time for CRRA model, for fixed values ranging from 1-3.

\begin{tabular}{lcccccccc}
\hline $\mathrm{T}$ & $\mathrm{Z}$ & $\mathrm{U}$ & $\mathrm{T}$ & $\mathrm{Z}$ & $\mathrm{U}$ & $\mathrm{t}$ & $\mathrm{Z}$ & $\mathrm{U}$ \\
0 & 1 & 0.01126233265 & 0 & 2 & 0.1801973224 & 0 & 3 & 0.9122489445 \\
1 & 1 & 0.01163316951 & 1 & 2 & 0.1861307122 & 1 & 3 & 0.9422867306 \\
5 & 1 & 0.01324271030 & 5 & 2 & 0.2118833648 & 5 & 3 & 1.072659535 \\
10 & 1 & 0.01557131915 & 10 & 2 & 0.2491411064 & 10 & 3 & 1.261276851 \\
15 & 1 & 0.01830939246 & 15 & 2 & 0.2929502793 & 15 & 3 & 1.483060789 \\
20 & 1 & 0.02152893078 & 20 & 2 & 0.3444628925 & 20 & 3 & 1.743843393 \\
25 & 1 & 0.02531459532 & 25 & 2 & 0.4050335251 & 25 & 3 & 2.050482221 \\
30 & 1 & 0.02976593415 & 30 & 2 & 0.4762549464 & 30 & 3 & 2.411040666 \\
35 & 1 & 0.03500000000 & 35 & 2 & 0.5600000000 & 35 & 3 & 2.835000000 \\
\hline
\end{tabular}

Table 6. Values for optimal policy, dual variable and continuous time for CARA model.

\begin{tabular}{lccccccccccccccc}
\hline $\mathrm{U}$ & 1.57 & 1.52 & 1.51 & 1.50 & 1.49 & 1.39 & 0.38 & 0.38 & 0.34 & 0.32 & 0.46 & 0.42 & 0.41 & 0.34 & 0.32 \\
$\mathrm{Z}$ & 1 & 2 & 3 & 4 & 5 & 6 & 7 & 8 & 9 & 10 & 11 & 12 & 13 & 14 & 15 \\
$\mathrm{t}$ & 0 & 1 & 2 & 3 & 4 & 5 & 6 & 7 & 8 & 9 & 10 & 11 & 12 & 13 & 14 \\
\hline $\mathrm{U}$ & 1.46 & 0.42 & 0.41 & 0.34 & 0.32 & 1.41 & 0.40 & 1.39 & 0.39 & 0.38 & 0.38 & 0.34 & 0.32 & 0.46 & 0.42 \\
$\mathrm{Z}$ & 16 & 17 & 18 & 19 & 20 & 21 & 22 & 23 & 24 & 25 & 26 & 27 & 28 & 29 & 30 \\
$\mathrm{t}$ & 15 & 16 & 17 & 18 & 19 & 20 & 21 & 22 & 23 & 24 & 25 & 26 & 27 & 28 & 29 \\
\hline
\end{tabular}

Table 7. Values for optimal policy, dual variable and continuous time for CARA model, when there is orthogonal relationship between time and stock.

\begin{tabular}{lccccccccccccccc}
\hline $\mathrm{U}$ & 0.47 & 0.042 & 0.041 & 0.040 & 0.039 & 0.038 & 0.038 & 0.34 & 0.32 & 0.46 & 0.42 & 0.41 & 0.34 & 0.32 & 0.46 \\
$\mathrm{Z}$ & 1 & 2 & 3 & 4 & 5 & 6 & 7 & 8 & 9 & 10 & 11 & 12 & 13 & 14 & 15 \\
$\mathrm{t}$ & 0 & 1 & 2 & 3 & 4 & 5 & 6 & 7 & 8 & 9 & 10 & 11 & 12 & 13 & 14 \\
\hline $\mathrm{U}$ & 0.42 & 0.41 & 0.34 & 0.32 & 0.41 & 1.40 & 0.39 & 0.39 & 0.38 & 0.38 & 0.34 & 0.32 & 0.46 & 0.42 & 0.42 \\
$\mathrm{Z}$ & 16 & 17 & 18 & 19 & 20 & 21 & 22 & 23 & 24 & 25 & 26 & 27 & 28 & 29 & 30 \\
$\mathrm{t}$ & 15 & 16 & 17 & 18 & 19 & 20 & 21 & 22 & 23 & 24 & 25 & 26 & 27 & 28 & 29 \\
\hline
\end{tabular}

Table 8. Values for optimal policy, dual variable and continuous time for CARA model, when there no payment was made to the next of kin of the dead contributors.

\begin{tabular}{cccccccccccccccc}
\hline $\mathrm{U}$ & 0.047 & 0.042 & 0.041 & 0.040 & 0.039 & 0.039 & 0.038 & 0.38 & 0.34 & 0.32 & 0.46 & 0.42 & 0.41 & 0.34 & 0.32 \\
$\mathrm{Z}$ & 1 & 2 & 3 & 4 & 5 & 6 & 7 & 8 & 9 & 10 & 11 & 12 & 13 & 14 & 15 \\
$\mathrm{t}$ & 0 & 1 & 2 & 3 & 4 & 5 & 6 & 7 & 8 & 9 & 10 & 11 & 12 & 13 & 14 \\
\hline $\mathrm{U}$ & 0.46 & 0.42 & 0.41 & 0.34 & 0.32 & 1.41 & 0.40 & 0.39 & 0.39 & 0.38 & 0.38 & 0.34 & 0.46 & 0.32 & 0.46 \\
$\mathrm{Z}$ & 16 & 17 & 18 & 19 & 20 & 21 & 22 & 23 & 24 & 25 & 26 & 27 & 28 & 29 & 30 \\
$\mathrm{t}$ & 15 & 16 & 17 & 18 & 19 & 20 & 21 & 22 & 23 & 24 & 25 & 26 & 27 & 28 & 29 \\
\hline
\end{tabular}




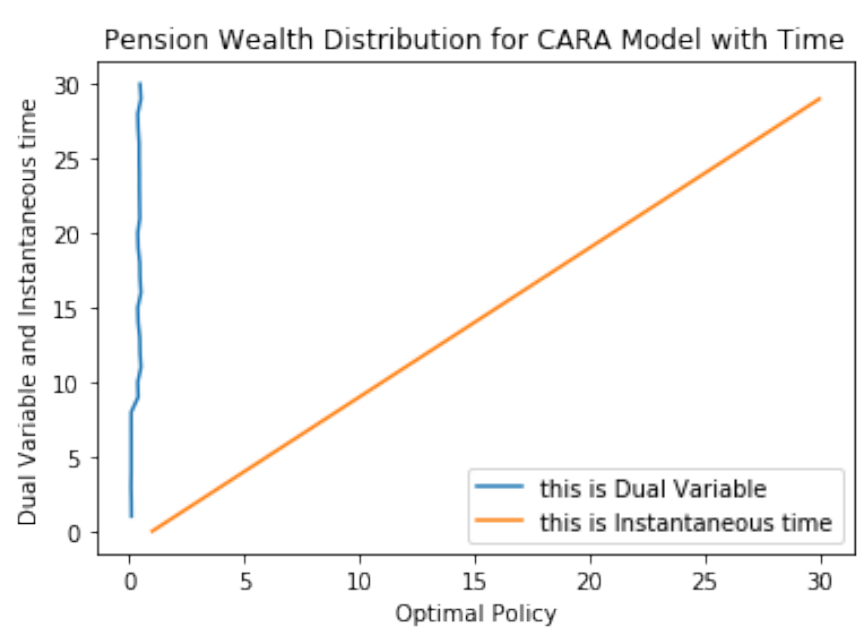

Figure 3. The graph of dual variable and instantaneous time against optimal policy for CRRA Model, when there is no payment made to the next of kin of the dead contributors.
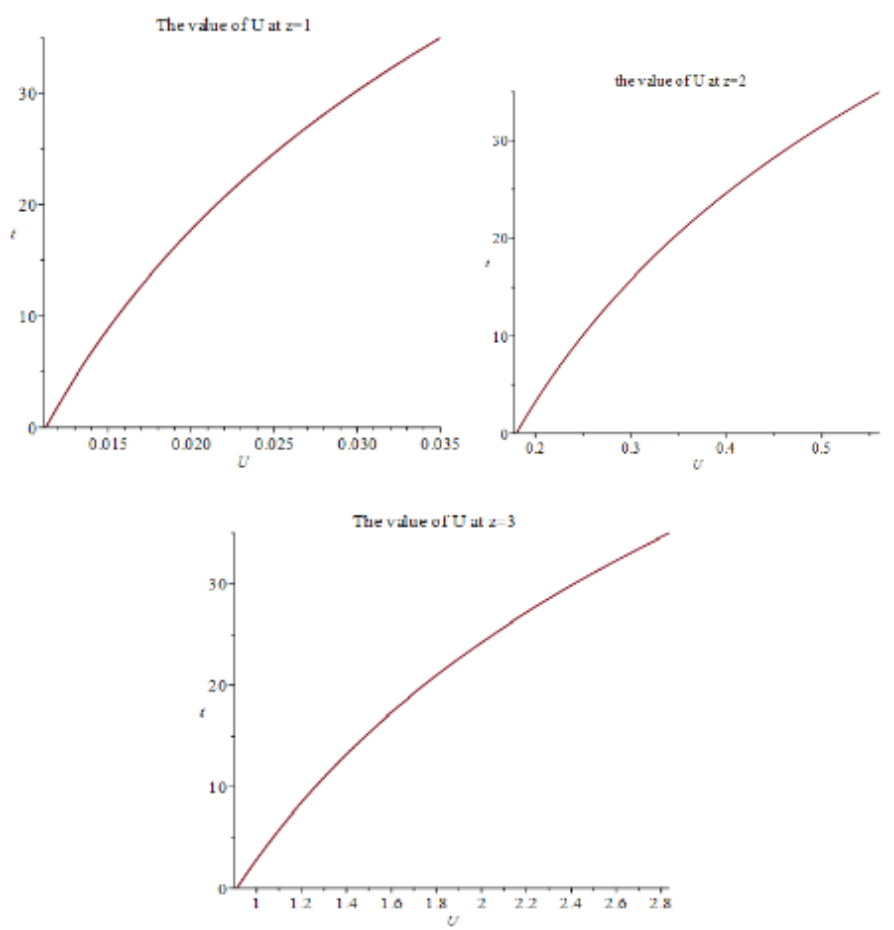

Figure 4. Two dimensional view of CRRA Model, for fixed values of the dual variable.

period. This suggests that diversification of investments should be advised in order to enhance investment returns.

There exists a modifying factor, which depends on both time and the coefficient of the utility function, just like in [10], and this modifying factor controls investment decision of the PPM. Particularly, it reflects the investor's decision to hedge the volatility risk.

For CRRA Utility Function in the Accumulation Phase under Inflationary Market, the effect of inflation on pension wealth investment; the CRRA utility function has little or no effect on

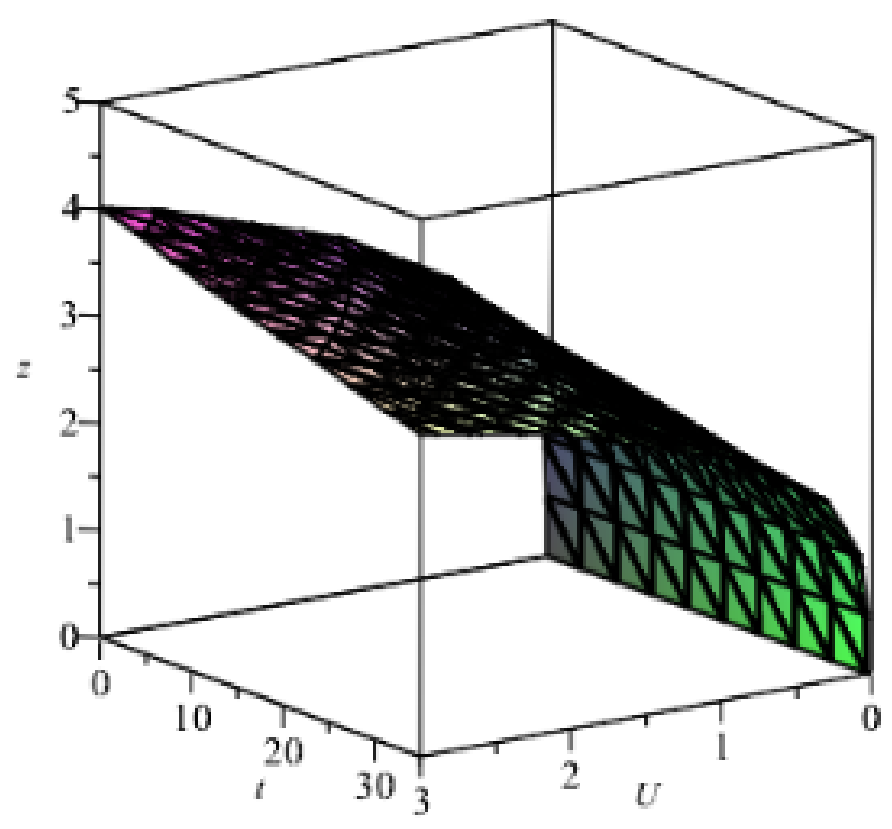

Figure 5. The three dimensional view of the CRRA model, using Maple of Table 5 .

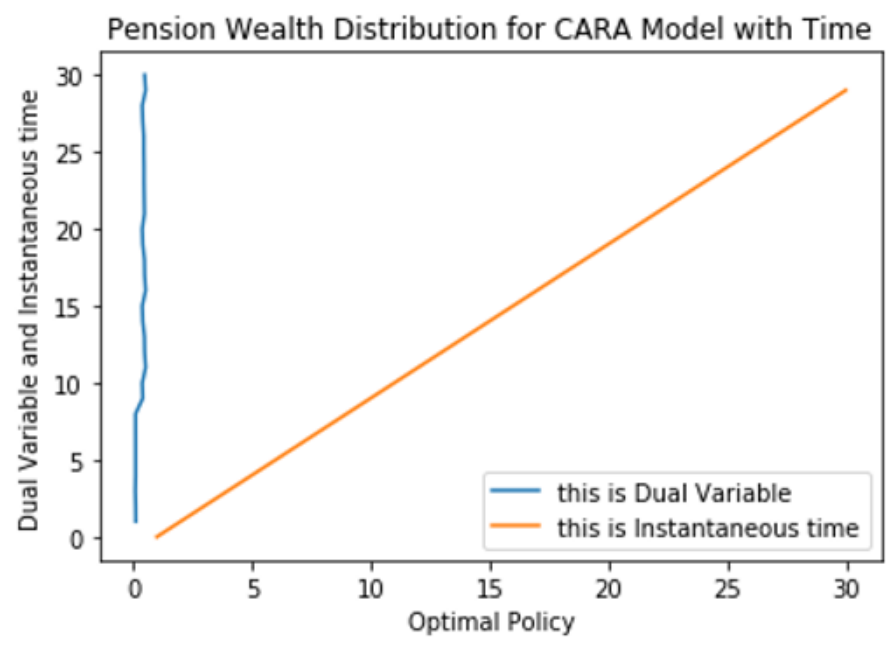

Figure 6. The graph of dual variable and instantaneous time against optimal policy for CARA Model.

the investment strategy. Recall from [4], the coefficients $d_{1}, d_{2}$ degenerates to $\frac{4 b}{2 k_{1}}$ and zero, in the absence of the coefficient of the CRRA (i.e., as $p \rightarrow 0$ ), however, in this work, even in the presence of the coefficient of CRRA, the coefficients $d_{1}, d_{2}$ are already degenerate. For the effect of hedging, using Inflationindexed bond and Inflation-linked stock, the Inflation-indexed Bond and Inflation-linked Stock served as a hedging mechanism against inflation. In the absence of the coefficient of the CRRA (i.e., as $\rightarrow 0$ ), the coefficients $d_{1}, d_{2}$, still retains its value (i.e., will never degenerate further than this). There exists also a modifying factor, which depends on time, only, just like in [12], for CRRA utility function, and this modifying factor controls investment decision of the PPM. There exists a modifying factor which depends on both time and the coefficient 


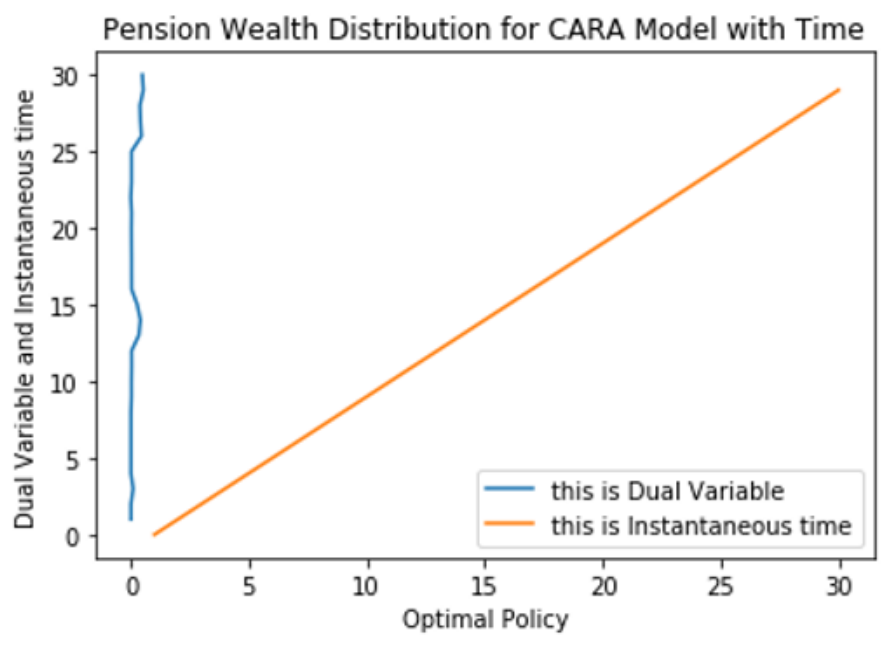

Figure 7. The graph of dual variable and instantaneous time against optimal policy for CARA Model, when there is orthogonal relationship between time and stock.

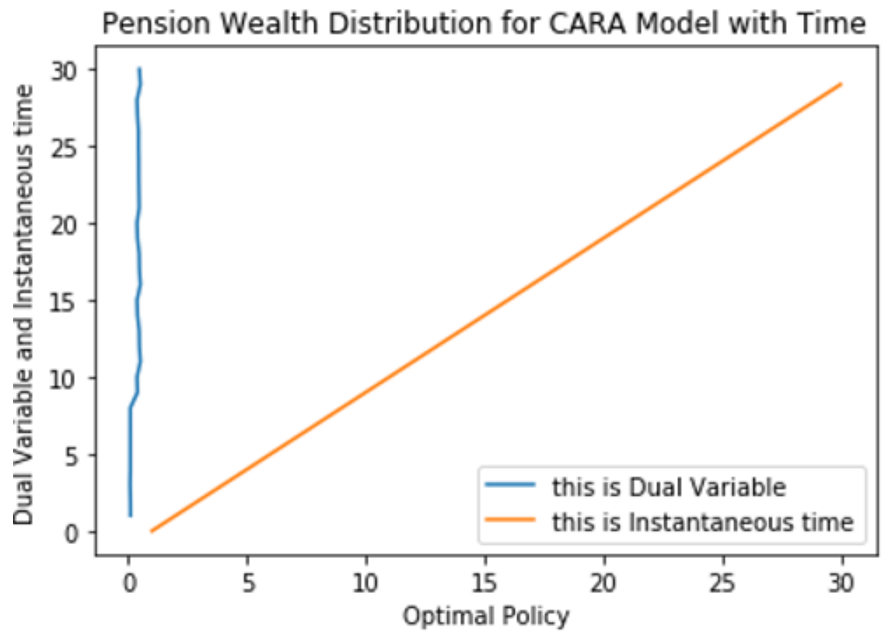

Figure 8. The graph of dual variable and instantaneous time against optimal policy for CARA Model, when no payment was made to the next of kin of the dead contributors.

of the CARA utility function as in [10], for the CARA utility function. This modifying factor controls investment decision of the PPM. Particularly, it reflects the investor's decision to hedge the volatility risk. There exists an elastic parameter that takes values other than unity. More so, the Inflation-linked Bond and Inflation-indexed Stock served as hedging mechanism in the optimization of Pension wealth. Lastly, comparing the utilities in the noninflationary market, during decummulation phase, we conclude that the policy, $u_{s}^{*}(t)$ due to CRRA utility function is the optimal policy, while in that of the inflationary market, during accumulation phase, the policies, $u_{s}^{*}(t)$, and $u_{B}^{*}(t)$ due to CRRA utility function is not the best fit, based on the assumptions of our models .Based on the result above, there exists some optimal policies that can permit energetic retirees to invest in risky assets.

\section{Conclusion}

For the noninflationary market, we studied and modified the optimal investment strategy for annuity contract under the constant elasticity of variance by [10], and proved that the elastic parameter takes values other than unity. We constructed an optimal investment strategy in the pension benefit distribution phase, for both CRRA and CARA utility functions, and the associated utility functions (see equations ??, 20, 21, and 21). We tested for sensitivity of some parameters in both the investment strategies and the utility functions (see sensitivity analysis). We simulated and compared the expected utilities of the accumulation phase (see Figures 1 through 8 above using Tables 1 through 8 as appropriate). Based on these comparisons, we conclude that the investment strategy with the CRRA utility function provides the optimal strategy, though, the investment returns is still low, and this suggests that diversification of investment should be advised to enhance returns. More so, there exists an investment strategy that permits investments into risky assets, even after retirement. We conclude that both for CRRA and CARA utility, the orthogonal relationship between stock and time have the same effect on contributor's satisfaction. There exists a modifying factor which depends on both time and the coefficient of CRRA utility function, and also depends on time, only just like in [10], and this modifying factor controls investment decision of the Pension Plan Member. Particularly, it reflects the investor's decision to hedge the volatility risk.

For inflationary market, we constructed an optimal investment strategy in the pension accumulation phase, for the CRRA utility function and the associated expected utility functions (see equations 23 and 24). We also tested for sensitivity of parameters in both the investment strategies and the utility functions. We conclude that the CRRA utility approach has little or no effect on the investment strategy, and this depicts the effect of inflation on optimal investment strategy. More so, the Inflation-linked Bond and the Inflation-Indexed Stock serve as hedging mechanism in the optimization of pension wealth.

As a result of uncertainties of the markets, the substitute investment and the encouragement of higher investment yield, for the noninflationary markets, we recommend diversified investment of pension wealth into assets like government Bond and even corporate (private) Bond. For the inflationary market (in order to cushion the effect of inflation on pension wealth generation in a DC pension scheme) we recommend the investigation of the effect of extra stochastic contributions.

\section{Acknowledgments}

We thank the referees for the positive enlightening comments and suggestions, which have greatly helped us in making improvements to this paper.

\section{References}

[1] Nigerian Pension Reform Act of (2004). 
[2] A. J. G. Cairns, D. Blake \& K. Dowd "Stochastic lifestyling: optimal dynamic asset allocation for defined contribution pension plans," Journal of Economic Dynamics \& Control 30 (2006) 843.

[3] L. Wang \& Z. Chen "Nash Equilibrium Strategy for a DC Pension Plan with State-Dependent Risk Aversion: A Multi period Mean-Variance Framework", Hindawi Discrete Dynamics in Nature and Society Article ID 7581231, (2018) 17 https://doi.org/10.1155/2018/7581231.

[4] Z. Chubing \& R. Ximing "Optimal investment strategies for DC pension with stochastic salary under affine interest rate model", Hindawi Publishing Corporation (2013) $15 \mathrm{http}: / / \mathrm{dx}$.doi.org/10.1155/2013/297875.

[5] P. Battocchio \& F. Menoncin "Optimal pension management in a stochastic Framework", Insurance 34 (2004) 79.

[6] J. F. Boulier, S. Huang \& G. Taillard "Optimal management under stochastic interest rates: the case of a protected defined contribution pension fund", Insurance 28 (2001) 173.

[7] G. Deelstra, M. Grasselli \& P. F. Koehl "Optimal investment strategies in the presence of a minimum guarantee", Insurance 33 (2003) 189.

[8] J. Gao "Stochastic optimal control of DC pension funds", Insurance $\mathbf{4 2}$ (2008) 1159.

[9] J. Xiao, Z. Hong \& C. Qin "The constant elasticity of variance (CEV) model and the Legendre transform-dual solution for annuity contracts", Insurance 40 (2007) 302

[10] J. Gao "Optimal portfolios for DC pension plans under a CEV model", Insurance: Mathematics and Economics 44 (2009) 479.

[11] O. Basimanebotlhe \& X. Xue "Stochastic Optimal Investment under Inflationary Market with Minimum Guarantee for DC Pension Plans", Journal of Mathematics Research 7 (2013) 1.

[12] J. Gao "Optimal investment strategy for annuity contracts under the constant elasticity of variance (CEV) model", Insurance 45 (2009) 9.

[13] K. N. C. Njoku \& B. O. Osu "On the Modified Optimal Investment Strategy for Annuity Contracts under the Constant Elasticity of Variance (CEV) Model", Earthline Journal of Mathematical Sciences 1 (2019) 63.

[14] B. O. Osu, K. N. C. Njoku \& B. I. Oruh "On the Effect of Inflation and Impact of Hedging on Pension Wealth Generation Strategies under the Geometric Brownian Motion Model", Earthline Journal of Mathematical Sciences 1 (2009) 119.

[15] M. Jonsson \& R. Sircar "Optimal investment problems and Volatility homogenization approximations", in Modern Methodsin Scientific Computing and Applications 75 (2002) 255.

[16] E. E. Akpanibah, B.O. Osu, K. N .C. Njoku \& E. O. Akak "Optimization of Wealth Investment Strategies for DC Pension Fund with Stochastic Salary and Extra Contributions", International Journal of Partial Differential Equations and Applications 5 (2017) 33.

[17] K. N. C. Njoku, B. O. Osu, E. E. Akpanibah \& R. N. Ujumadu "Effect of Extra Contribution On Stochastic Optimal Investment Strategies for DC Pension with Stochastic Salary under the Affine Interest Rate Model", Journal of Mathematical Finance 7 (2017) 821.

[18] P. K. Mwanakatwe, L Song \& E Hagenimana "Management Strategies for a Defined Contribution Pension Fund under the Hull-White Interest Rate Model", Advances in Intelligent Systems Research (AMMS) 153 (2017) 239. 